\title{
WILDLIFE ROAD KILLS
}

\section{by JAMES DONOVAN*}

In the past, I have often wondered how great was the loss of wildlife to collisions with automobiles. Finally in 1974 while living at Broadview and working in Whitewood I had the opportunity to make some observations on the extent of road kills. During the last half of June I observed an increased number of road killed animals, and decided for the month of July I would count and record the numbers and species of road killed animals. Table 1 represents observations from my twenty trips (28 miles each day) during July, 1974.

Of the Richardson's Ground squirrels hit by cars nearly all were young-of-the-year, and 18 of the 37 were killed on only two days (approximately 1 week apart). In both cases, there had been a light shower during the day or evening previous.

The two coyotes were found about 100 yards from each other but not on the same day. The two porcupines, skunks, grackles and the three Cro seemed to suffer the same fate at ce tain places along the highway but different days.

The unidentified birds and ma mals were in most cases little mo than blotches on the highway. Th were difficult or impossible to ident more accurately than bird or mamm

This list totals 112 individuals there may have been a great ma more that were hit and killed or jured but not observed. Many, doubt, were knocked off the road a never counted; or disintegrated, were eaten before being observed: were lodged in car grilles.

If one were to determine the num of miles of primary and second road in western Canada and use table of road kills I have presented some fraction of it), an estimate $f$ highway mortality of wildlife would e in the millions for any one year.

Table 1. Road kills near Whitewood, Saskatchewan

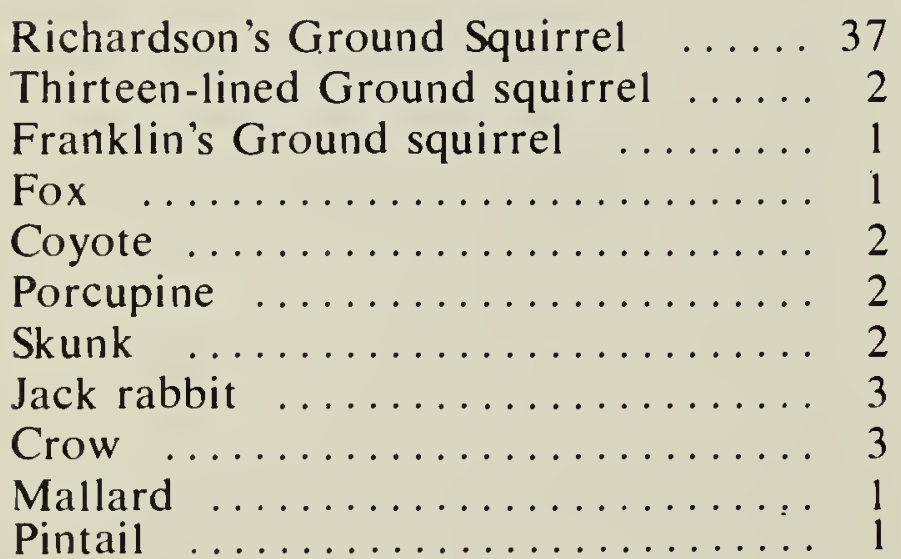

Kingbird $\ldots \ldots \ldots \ldots \ldots \ldots \ldots 2$

House sparrow $\ldots \ldots \ldots \ldots \ldots \ldots$

Canary? ................... 1

Small unidentified mammals (mouse size)

Small unidentified birds (sparrow size) $\ldots \ldots \ldots \ldots \ldots \ldots$

Grackle ................... 2

Hereford Cow ..............

Dog .................... 1

TOTAL

\footnotetext{
* Department of Cooperation

1091 - 103ru Street,

North Battleford, Sask.

S9A IK3.
} 